\section{$\underset{\substack{\text { hommes } \\ \text { \& migrations }}}{ }$}

\section{Hommes \& migrations}

Revue française de référence sur les dynamiques

migratoires

1332 | 2021

Ce qui s'oublie et ce qui reste

\title{
Présences africaines au long cours
}

\section{Marie Poinsot}

\section{(Q) OpenEdition \\ Journals}

\section{Édition électronique}

URL : https://journals.openedition.org/hommesmigrations/12099

DOI : 10.4000/hommesmigrations. 12099

ISSN : 2262-3353

\section{Éditeur}

Musée national de l'histoire de l'immigration

\section{Édition imprimée}

Date de publication : 1 janvier 2021

Pagination : 1

ISBN : 978-2-919040-54-4

ISSN : $1142-852 X$

\section{Référence électronique}

Marie Poinsot, «Présences africaines au long cours », Hommes \& migrations [En ligne], 1332 | 2021, mis en ligne le 01 janvier 2021, consulté le 26 juillet 2021. URL : http://journals.openedition.org/ hommesmigrations/12099; DOI : https://doi.org/10.4000/hommesmigrations.12099 


\section{Édito}

\section{Présences africaines au long cours}

Marie Poinsot,

rédactrice en chef de la revue.

\section{La Saison Africa2020 à l'honneur}

Le printemps s'inaugure avec l'exposition Ce qui s'oublie et ce qui reste que le Musée national de l'histoire de l'immigration propose en partenariat avec le Musée d'art contemporain africain Al Maaden (MACAAL) de Marrakech à l'occasion de la Saison Africa2020. En ouverture, N'Goné Fall, commissaire générale de cette saison, nous engage à changer «à $360^{\circ}$ » notre perception d'une Afrique balkanisée et dans l'impasse en partageant ce que les Africains ont envie de dire sur les enjeux contemporains, notamment l'histoire, le territoire, la citoyenneté. Pour cela, le Musée a choisi de mettre en perspective des œuvres d'artistes contemporains issus du continent africain qui interrogent les migrations de populations qui partent hors d'Afrique, les transmissions ou omissions de leurs cultures et identités dans un monde interconnecté. Le portfolio présente les œuvres de l'exposition. Meriem Berrada et Isabelle Renard, les co-commissaires de l'exposition, nous éclairent sur les ressorts symboliques et esthétiques d'une création vive, extravagante et parfois iconoclaste. La diversité des regards nous interpelle, comme toute avant-garde qui s'émancipe des canaux de l'art occidental.

\section{La revue partage avec l'Afrique un intérêt commun}

Née des Cahiers Nord-africains, l'ADN de la revue s'est constitué autour des migrations maghrébines en France, perçues comme l'immigration par excellence. Plus récemment, les migrations internes à l'Afrique, qui composent l'essentiel des flux du continent, ont donné lieu à un numéro réalisé majoritairement à partir de la recherche africaine ( $\left.n^{\circ} 1279\right)$. Les présences africaines à l'extérieur du Continent s'expriment à travers les diasporas. Les 50 ans des Indépendances africaines ont donné le coup d'envoi d'une série de numéros sur les flux migratoires en provenance de l'Afrique, que ce soient l'immigration subsaharienne vers la France ( $\left.n^{\circ} 1286-87\right)$, l'immigration algérienne ( $n^{\circ} 1295$ et $n^{\circ} 1298$ ), les diasporas marocaines ( $n^{\circ} 1303$ ) et la migration qualifiée dans la mondialisation (n 1307). Les migrations africaines ont fait également l'objet d'examens thématiques sur les pratiques culinaires ( $n^{\circ} 1283$ ) ou linguistiques ( $n^{\circ} 1288$ ), le sport ( $n^{\circ} 1289$ ), la mode ( $n^{\circ} 1310$ ), la patrimonialisation ( $\left.n^{\circ} 1293\right)$ et la création littéraire ( $\left.n^{\circ} 1329\right)$.

\section{Créativité, modernité et africanité}

Dans cette publication, les diasporas africaines sont abordées sous l'angle de leur créativité. Les diasporas africaines ont construit des passerelles culturelles entre l'Afrique, l'Europe, les Amériques malgré les violences destructrices de la traite esclavagiste et de la colonisation, qui sont réactivées par les circulations migratoires dans le sillage de la décolonisation. Jacques Barou et Jean-Baptiste Meyer, en guise d'introduction du dossier scientifique, démontrent comment le transnationalisme des diasporas est un facteur déterminant de création culturelle, d'engagement politique et d'innovation. La créativité résulte des efforts de décentrement et d'adaptation aux nouveaux contextes de vie. Les carrières des intellectuels et des artistes, plus visibles que celles des travailleurs immigrés, s'enrichissent de leurs déplacements, souvent à la marge des institutions, et de la confrontation avec l'altérité. Les talents se bonifient à l'extérieur du continent en inventant les contours d'une africanité, faite d'hybridation et de syncrétisme, qui s'inscrit en terre étrangère dans la modernité culturelle. Les liens diasporiques tissés avec le continent africain - symbole du foyer original des diasporas et espaces de ressources plurielles - favorisent aussi les volontés d'y entreprendre à rebours des projets économiques ou culturels.

\section{Hommage à Blandine Renaud}

Nous avons appris le décès de Blandine Renaud, fondatrice de Dif'Pop puis de Pollen, femme dynamique et âme de la diffusion des revues en France. La revue s'associe à ses proches pour regretter sa disparition qui laisse les revues orphelines. 